\title{
Anti-Onchocerca activity and phytochemical analysis of an essential oil from Cyperus articulatus L
}

Jonathan Alunge Metuge ${ }^{1}$, Kennedy D Nyongbela², James A Mbah², Moses Samje', Ghislain Fotso ${ }^{3}$, Smith B Babiaka ${ }^{2}$ and Fidelis Cho-Ngwa ${ }^{1 *}$

\begin{abstract}
Background: The lack of a safe and effective adult worm drug and the emergence of resistant animal parasite strains to the only recommended drug, the microfilaricide, ivermectin put many at risk of the devastating effects of the onchocerciasis. The present study was undertaken to investigate the acclaimed anti-Onchocerca activity of the roots/rhizomes of Cyperus articulatus in the traditional treatment of onchocerciasis in North Western Cameroon and to assess the plant as a new source of potential filaricidal lead compounds.

Methods: Crude extracts were prepared from the dried plant parts using hexane, methylene chloride and methanol. The antifilarial activity was evaluated in vitro on microfilariae (Mfs) and adult worms of the bovine derived Onchocerca ochengi, a close relative of Onchocerca volvulus. The viabilities of microfilariae and adult male worms were determined based on motility reduction, while for the adult female worms the viability was based on the standard MTT/formazan assay. Cytotoxicity of the active extract was assessed on monkey kidney epithelial cells in vitro and the selectivity indices (SI) were determined. Acute toxicity of the promising extract was investigated in mice. Chemical composition of the active extract was unraveled by GC/MS analysis.
\end{abstract}

Results: Only the hexane extract, an essential oil exhibited anti-Onchocerca activity. The oil killed both the microfilariae and adult worms of $O$. ochengi in a dose manner dependently, with $I_{50} S$ of $23.4 \mu \mathrm{g} / \mathrm{ml}$ on the Mfs, $23.4 \mu \mathrm{g} / \mathrm{ml}$ on adult male worms and $31.25 \mu \mathrm{g} / \mathrm{ml}$ on the adult female worms. Selectivity indices were 4, 4, and 2.99 for Mfs, adult males and adult females, respectively. At a single limit dose of $2000 \mathrm{mg} / \mathrm{kg}$ body weight, none of 6 mice that received the essential oil by gavage died. GC/MS analysis revealed the presence of terpenoids, hydrocarbons and fatty acids or fatty acid derivatives as components of the oil.

Conclusions: The essential oil from the roots/rhizomes of Cyperus articulatus is active against O. ochengi microfilariae and adult worms in vitro in a dose dependent manner, hence may provide a source of new anti-filarial compounds. The results also support the traditional use of $C$. articulatus in the treatment of human onchocerciasis.

Keywords: Essential oil, Human onchocerciasis, Cyperus articulatus, Phytochemical analysis

\footnotetext{
*Correspondence: chongwa_ub@yahoo.co.uk

'ANDI Centre of Excellence, Biotechnology Unit, Faculty of Science,

University of Buea, P.O. Box 63, Buea, Cameroon

Full list of author information is available at the end of the article
} 


\section{Background}

Onchocerciasis or river blindness is the second leading infectious cause of blindness in humans. According to the World Health Organization, an estimated 37 million people are infected with the parasite and about 300,000 are blind from onchocerciasis [1]. Ivermectin was shown to be both safe and effective in the treatment of onchocerciasis and has become the drug of choice for control by mass drug administration (MDA) strategy [2]. However, ivermectin is only effective against the microfilarial stage (Mfs) of the parasite and prolonged annual ivermectin therapy of at least 10 to 15 years has been predicted to be required for clearance of onchocerciasis from a human population [3]. This makes the search for a drug that kills the adult worm (a cure) a research priority area. During mass treatment of onchocerciasis with ivermectin in forested zones of Central Africa, several adverse events, including encephalopathy and deaths were reported in patients co-infected with $L$. loa [4]. The potential development of ivermectin-resistant strains of the parasite also demands the identification of alternative drug candidates for onchocerciasis control [5].

A new chemotherapeutic approach to onchocerciasis uses antibiotics against the essential Wolbachia endobacteria present in many filariae. Doxycycline has been shown to exhibit a macrofilaricidal effect on $O$. volvulus after a daily dosage for six weeks [6]. Although a report on community-directed delivery of doxycycline for the treatment of onchocerciasis in Cameroon indicated that delivery and compliance are achievable for six weeks [7], it must be recognized that there are restrictions on the use of this antibiotic on pregnant women, lactating mothers and children less than 9 years of age [8].

It has been suggested that natural plant products may provide a good alternative source of antifilarial medicines because they are cheap, readily available, have negligible side effects $[9,10]$ and compliance rate may be high since they are indigenous medicines. Natural products have shown great potentials in treating infectious diseases in humans [11]. Studies on the chemical composition and biological activity of Cyperus articulatus suggest that rhizomes of the plant have anti-plasmodial, antibacterial, anti-fungal, as well as anti-convulsant actions [12-15]. However, the anti-onchocercal activity of $C$. articulatus has not been evaluated. It is against this backdrop that this study was aimed at evaluating the antifilarial activity of the roots and rhizomes of Cyperus articulatus, a plant used in the traditional treatment of onchocerciasis in North Western Cameroon. In its local use, the roots and rhizomes of the plant are chopped, dried, boiled in water and taken as a decoction. The activity was evaluated on the Mfs and adult worms of Onchocerca ochengi, the closest relative of $O$. volvulus and best model for anti-O. volvulus drug screens [16].

\section{Methods}

\section{Collection and identification of plant}

The roots and rhizomes of Cyperus articulatus were collected from inland valleys at Sehn village, Ndu SubDivision in the North West Region of Cameroon in February 2012, based on ethnopharmacological information. The local name of the plant is "Ndfu". The voucher specimen was deposited at the National Herbarium in Yaoundé and assigned voucher number 19450/SRF-CAM.

\section{Preparation of plant extracts}

The roots along with the rhizomes of Cyperus articulatus were air-dried for three weeks and ground to fine powder. The powder was weighed and macerated for 48 hours, three times per solvent and sequentially in hexane, methylene chloride and methanol, following increasing solvent polarity. The mixture was filtered and the filtrate concentrated under reduced pressure using a rotary evaporator (BUCHI Rotavapor R-200, Switzerland) set at 150 mbar. The hexane and methanol extracts were concentrated under reduced pressure at $45^{\circ} \mathrm{C}$ while the methylene chloride extract was concentrated at $50^{\circ} \mathrm{C}$ without the pressure reduction. Residual solvent was removed by drying in air at room temperature $\left(23-25^{\circ} \mathrm{C}\right)$ for 6 days. The extracts were weighed and stored at $-20^{\circ} \mathrm{C}$ until used.

\section{Isolation of $O$. ochengi adult worms}

The isolation of $O$. ochengi adult worms was done as described previously [17]. The duration from the slaughtering of a cow to the harvesting of parasites from the skin was always less than 2 hours to ensure full parasite viability. Briefly, fresh pieces of umbilical cattle skin with palpable nodules bought from local slaughterhouses were washed, drained and sterilized with $70 \%$ ethanol. O. ochengi adult worms were carefully scraped out of the nodules as single masses and temporarily submerged in $1 \mathrm{~mL}$ complete culture medium, CCM [RPMI-1640 (SIGMA, USA) supplemented with $25 \mathrm{mM}$ HEPES, $2 \mathrm{~g} / \mathrm{L}$ sodium bicarbonate, $2 \mathrm{mM}$ L-glutamine, $5 \%$ new born calf serum (SIGMA, USA), 150 units $/ \mathrm{mL}$ penicillin, $150 \mu \mathrm{g} / \mathrm{mL}$ streptomycin and $0.5 \mu \mathrm{g} / \mathrm{mL}$ amphotericin B (SIGMA, USA), pH 7.4)] using 24-well plates. The adult worms were allowed in the culture medium overnight in a $\mathrm{CO}_{2}$ incubator, during which period the male worms migrated out of the nodular masses. Only wells containing viable worms received treatment with the plant extract. Worms from putrefied nodules were discarded. The viability of worms retained for the assay was ascertained by visual and microscopic examination of adult worm and microfilarial motility using an inverted microscope. 


\section{Isolation of $O$. ochengi microfilariae}

The cattle skin was obtained as described for adult worms. About 5 skin snips were obtained from different locations of the skin and incubated separately in small amounts of CCM for 30 minutes. Emerged Mfs were qualified and quantified for $O$. ochengi species with the aid of an inverted microscope. A selected piece of skin, rich in $O$. ochengi Mfs was carefully shaved with a razor blade and rinsed with distilled water. It was dabbed with a clean tea cloth to eliminate excess moisture and covered entirely with $70 \%$ ethanol. The latter was allowed to evaporate completely in a horizontal flow sterile hood. The ethanol treatment was repeated once. The sterilized skin was tautly attached onto an autoclaved, cylindrical piece of wood using autoclaved thumb nails and close (about $1 \mathrm{~mm}$ apart) criss-cross cuts were made into the epidermis and dermis. The assembly was incubated in the culture medium for 4-6 hours. The emerged and highly motile $O$. ochengi microfilariae were concentrated by centrifugation at $400 \times g$ for 10 minutes and then quantified.

\section{Preparation of mammalian cells}

Monkey kidney epithelial cells (LLC-MK2) (ATCC, USA) were cultured at $37^{\circ} \mathrm{C}$ in humidified air with $5 \% \mathrm{CO}_{2}$ in a HeraCell-150 incubator (Thermo Electron, Germany) until the cell layer was almost confluent. The cells were rinsed with a solution of $0.125 \%$ trypsin and $0.5 \mathrm{mM}$ EDTA in medium 199 (Sigma, USA) and kept in the same mixture for less than 1 hour for them to be dislodged. The cell suspension was centrifuged at $560 \times g$ for 10 minutes, the supernatant discarded and the pellet re-suspended to $2 \times 10^{5}$ cells $/ \mathrm{ml}$ in CCM. The cell suspension was dispensed into 96-well microtitre plates $(200 \mu \mathrm{l} /$ well $)$ and kept in the incubator for 3-5 days for cells to grow and become fully confluent. These cells served as feeder layer for the Mfs assays and were also used for cytotoxicity studies.

\section{Preparation of stock solutions of plant extracts}

Twenty-five milligrams $(25 \mathrm{mg}$ ) of each crude extract was weighed and dissolved in microtubes containing $1 \mathrm{~mL}$ of $99.9 \%$ pure dimethyl sulfoxide (DMSO) (SIGMA, USA) to obtain stock solutions of $25 \mathrm{mg} / \mathrm{mL}$. Complete dissolution was achieved by vortexing. The solutions were stored at $4^{\circ} \mathrm{C}$ for a maximum of one week before they were used in the assays or were stored frozen at $-20^{\circ} \mathrm{C}$ in convenient aliquots prior to use.

\section{Anti-filarial screening of plant extracts Primary screens on adult worms}

This was done to eliminate inactive extracts. Adult worm assays were conducted in 24-well plates (NUNC, USA) at $37^{\circ} \mathrm{C}$ in humidified air containing $5 \% \mathrm{CO}_{2}$ for 5 days (120 hours) without change of medium. Nodular worm masses (each generally containing a few males and a female worm) were first put in the wells (with $1 \mathrm{ml}$ $\mathrm{CCM}$ at the time of worm isolation) without drug. One (1) $\mathrm{ml}$ of CCM containing $1 \mathrm{mg} / \mathrm{ml}$ of extract was then added into each of quadruplicate wells to give a single final concentration of $500 \mu \mathrm{g} / \mathrm{ml}$. Four nodular worm masses each, were used in the negative control (2\% DMSO in CCM only) and in the positive control $(10 \mu \mathrm{M}$ NYBC01, a gold conjugated compound) wells in which each well also received only one nodular worm mass. After 5 days incubation, adult male worm viability was assessed based on motility scores using an inverted microscope. Motility score was on a scale of 4 (vigorous or normal movement of whole worm, corresponding to $0 \%$ inhibition of worm motility), 3 (near normal movement of whole worm or $25 \%$ inhibition of worm motility), 2 (whole body of worm motile but sluggish i.e. $50 \%$ inhibition of worm motility), 1 (only head or tail of worm moving i.e. $75 \%$ inhibition of worm motility), 0 (completely immotile worm i.e. 100\% inhibition of worm motility). An extract was considered active on the adult male worm if there was a 100\% inhibition of motility; or moderately active for a motility inhibition of 50 - 99\%; and inactive if the inhibition was less than $50 \%$.

Adult female worm viability was assessed by the MTT/ formazan assay [18] in which each nodular worm mass was placed in a well of a 48-well microtitre plate containing $500 \mu \mathrm{l} /$ well of $0.5 \mathrm{mg} / \mathrm{ml}$ MTT (Sigma, USA) in incomplete RPMI culture medium, and then incubated in the dark at $37^{\circ} \mathrm{C}$ for 30 minutes. Adult female worm viability was taken as mean \% inhibition of formazan formation relative to negative control at $120 \mathrm{~h}$ post addition of plant extract. An extract was considered active on the adult female worm if there was a $90 \%$ or greater inhibition of formazan formation compared to the negative controls; or moderately active if the inhibition was $50-89 \%$. It was considered inactive if the inhibition was less than $50 \%$. Adult worm death positively correlates with inhibition of formazan formation.

\section{Primary screen on microfilariae}

The extracts were also tested on Mfs at a single concentration of $500 \mu \mathrm{g} / \mathrm{ml}$, in duplicate wells. The Mfs assay was conducted in 96-well microtitre plates $(15 \mathrm{mfs}$ in $200 \mu \mathrm{l} \mathrm{CCM}$ per well) at $37^{\circ} \mathrm{C}$ in humidified air containing $5 \% \mathrm{CO}_{2}$ for 5 days without any change of medium. Fully confluent monkey kidney epithelial cells, serving as feeder layer, were co-cultured with the Mfs. The medium used in preparing the feeder cell layer was removed by a swift decantation before fresh CCM containing plant extract $(100 \mu \mathrm{l})$ and worms $(100 \mu \mathrm{l})$ were immediately added. Ivermectin $(20 \mu \mathrm{g} / \mathrm{mL})$ and $2 \%$ DMSO served as the positive and negative controls respectively. Mfs motility reduction (viability reduction) were done on a scale of $100 \%$ (immotile), through $75 \%$ (only tail or head shaking occasionally), through 50\% (whole body motile, but sluggishly or with difficulties), to 25\% (almost vigorous) 
to $0 \%$ (fully vigorous motility). Scores were made every $24 \mathrm{~h}$, terminating at $120 \mathrm{~h}$ using an inverted microscope. Any culture with microbial contamination was not considered. Mfs viability was taken as the mean \% reduction at $120 \mathrm{~h}$ (day 5) after addition of drug. An extract was considered active if there was a $100 \%$ reduction in $\mathrm{mfs}$ motility; or moderately active for a motility reduction of $50-99 \%$; and inactive if the reduction was less than $50 \%$.

\section{Secondary screens on microfilariae and adult worms}

This was done to confirm the activity of active extracts and to determine their $\mathrm{IC}_{50}, \mathrm{IC}_{100}$ and selectivity index (SI) values. The extracts were retested as described under primary screens at serial dilutions from 500 to $7.81 \mu \mathrm{g} / \mathrm{ml}$. All assays were repeated at least thrice and the results obtained are the mean values at each concentration. The graphical analyses and $\mathrm{IC}_{50}$ values were determined using GraphPad Prism software (version 6).

\section{Toxicity studies \\ Cytotoxicity studies}

This was done as part of the Mfs assay on the active extracts through observations on the monkey kidney epithelial cells on day 5. An examination of the deformities and degree of detachment of the monkey kidney cells was done. Dead or deformed cells were usually detached from the bottom of the vessel and were rounded in shape. The $\mathrm{IC}_{50}$ values for these mammalian cells were determined graphically using data from microscopy. The selectivity index (SI) values were calculated using the ratio:

$\mathrm{SI}=\mathrm{IC}_{50}$ of drug on mammalian cell $/ \mathrm{IC}_{50}$ of drug on parasite $(\mathrm{Mfs})$

\section{Acute toxicity test}

This test was conducted in accordance with the Organisation for Economic Co-operation and Development (OECD) Guidelines for the Testing of Chemicals [19]. Briefly, six (6) nulliparous and non-pregnant female Balb/c mice, about 10 weeks old (averagely $20 \mathrm{~g}$ each) were kept in their cages for 5 days prior to dosing to allow for acclimatization to the animal house conditions. Food, but not water was withheld for 4 hours after which, the animals were weighed and the extract was administered orally by gavage at a limit dose of $2000 \mathrm{mg} / \mathrm{kg}$ body weight in a volume of $1 \mathrm{ml} / 100 \mathrm{~g}$ of body weight of mouse. The oil (active hexane extract) was dissolved in $100 \%$ hybrimax $^{\mathrm{TM}}$ DMSO (SIGMA USA) and diluted with sterile distilled water to give $2 \%$ DMSO solution. For negative control, six female mice were similarly dosed with 2\% DMSO diluted in sterile distilled water. After the test substance was administered, food was withheld for a further 2 hours. The animals were observed individually after dosing, once every 30 minutes during the first 4 hours, and daily thereafter for a total of 14 days. The animals were weighed every two days and observed for physical activity and behavior pattern, food and water intake, changes in skin and fur, eyes and mucous membranes, tremors, convulsions, diarrhea, salivation, lethargy, sleep, coma and death.

Gas chromatography-mass spectrometry (GC/MS) analysis The essential oil was subjected to GC-MS analysis for phytochemical studies. The GC/MS spectrometer (Agilent 6890/Hewlett-Packard 5975) was fitted with electron ionization (EI) module. Helium was used as the carrier gas at a flow rate of $1 \mathrm{ml} / \mathrm{min}$. The temperature was programmed at $80^{\circ} \mathrm{C}$ for $5 \mathrm{~min}$ then increased to $300^{\circ} \mathrm{C}$ at the rate of $15^{\circ} \mathrm{C} / \mathrm{min}$. The temperatures of the injector and EI detector $(70 \mathrm{eV})$ were $280^{\circ} \mathrm{C}$ and $300^{\circ} \mathrm{C}$, respectively. Then $29 \mu \mathrm{l}$ of the essential oil were injected into the fully calibrated GC/MS spectrometer. The compound identification was based on the comparison of the retention indices (determined relative to the retention times of series of n-alkanes), using an online natural products library.

\section{Results}

\section{Preparation of plant extracts}

Table 1 summarizes the percentage recovery of the different extracts of the roots/rhizomes of $C$. articulatus. The hexane extract $\left(\mathrm{CAR}_{\text {hex }}\right)$ was an essential oil, while the methylene chloride and methanol extracts were solids.

\section{Activity of extracts of roots/rhizomes C. articulatus in primary screens}

At $500 \mu \mathrm{g} / \mathrm{ml}$, only the essential oil was active against both microfilariae and adult worms (Table 2). The oil

Table 1 Yield of extracts of roots/rhizomes of $C$. articulatus using solvents of increasing polarity

\begin{tabular}{|c|c|c|c|c|c|c|}
\hline Name of plant & Plant part used & $\begin{array}{l}\text { Mass of dry powder or } \\
\text { residue (approx.)/g }\end{array}$ & Solvent & $\begin{array}{l}\text { Mass of } \\
\text { extract/g }\end{array}$ & $\begin{array}{c}\text { \% Recovery } \\
\text { of extract }\end{array}$ & Extract code \\
\hline \multirow[t]{3}{*}{ Cyperus articulatus } & Root/rhizome & 700 & Hexane & 26.2 & 3.74 & ${ }^{*}{ }^{*} C A R_{\text {hex }}$ \\
\hline & & 673.8 & Methylene chloride & 5.8 & 0.86 & $\mathrm{CAR}_{\mathrm{mc}}$ \\
\hline & & 668 & Methanol & 72.2 & 10.8 & $C A R_{\text {met }}$ \\
\hline
\end{tabular}

*The extract code CAR represents roots/rhizomes of Cyperus articulatus while the lower case letters of the code, hex, mc and met represent the solvents, hexane, methylene chloride and methanol, respectively. CAR $_{\text {hex }}$ is the essential oil. 
Table 2 Effect of extracts from roots/rhizomes of $C$. articulatus on 0 . ochengi in primary screens

\begin{tabular}{|c|c|c|c|c|}
\hline $\begin{array}{l}\text { Test substance } \\
\text { (concentration tested) }\end{array}$ & $\begin{array}{l}\% \text { Microfilarial } \\
\text { motility reduction }\end{array}$ & $\begin{array}{l}\% \text { Adult male worm } \\
\text { motility reduction }\end{array}$ & $\begin{array}{l}\% \text { Adult female } \\
\text { worm death }\end{array}$ & Comment \\
\hline $\mathrm{CAR}_{\text {hex }}(500 \mu \mathrm{g} / \mathrm{ml})$ & 100 & 100 & 100 & Macro- and microfilaricidal \\
\hline $\mathrm{CAR}_{\mathrm{mc}}(500 \mu \mathrm{g} / \mathrm{ml})$ & 25 & 50 & 25 & Inactive \\
\hline $\mathrm{CAR}_{\text {met }}(500 \mu \mathrm{g} / \mathrm{ml})$ & 25 & 75 & 25 & $\begin{array}{l}\text { Inactive on Mfs and adult females; } \\
\text { moderately active on adult males }\end{array}$ \\
\hline Ivermectin $(10$ g/ml) & 100 & NA & NA & Microfilaricidal \\
\hline 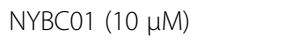 & 100 & 100 & 100 & Macro- and microfilaricidal \\
\hline DMSO (2\%) & 0 & 0 & 0 & Inactive \\
\hline
\end{tabular}

$\mathrm{NA}=$ Not applicable.

The gold-conjugated compound, NYBC01 was used as positive control for adult worm assay, while ivermectin was similarly used in the microfilarial assay. The drug diluent, $2 \%$ dimethyl sulphoxide (DMSO) was used as negative control.

completely inhibited Mfs and adult male worm motility after 24 hours incubation, and produced 100\% inhibition of formazan formation in adult female worms at 120 hours incubation. At $10 \mu \mathrm{M}, \mathrm{NYBC} 01$, a gold conjugated compound served as the positive control.

\section{Activity of the essential oil in secondary screens and cytotoxicity test}

The essential oil inhibited O. ochengi Mf and adult male worm motility, as well formazan formation by adult female worms in a dose dependent manner (Figure 1a-c).

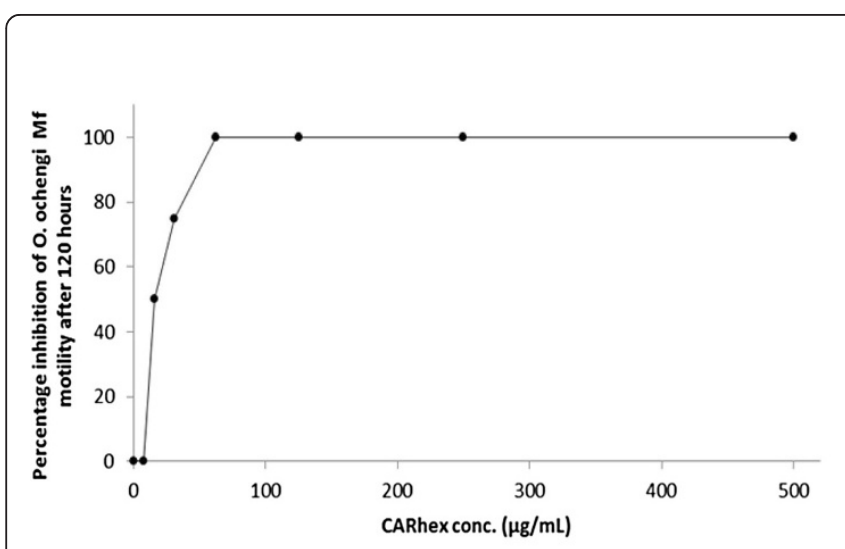

$\mathbf{a}$

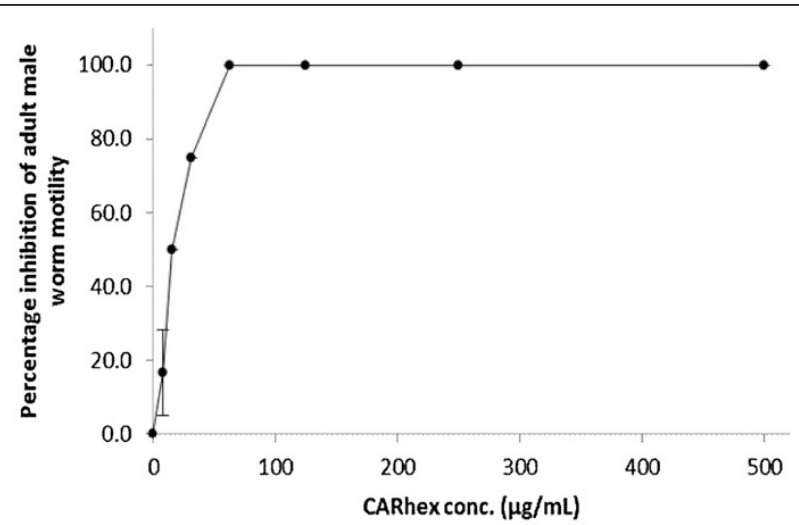

b

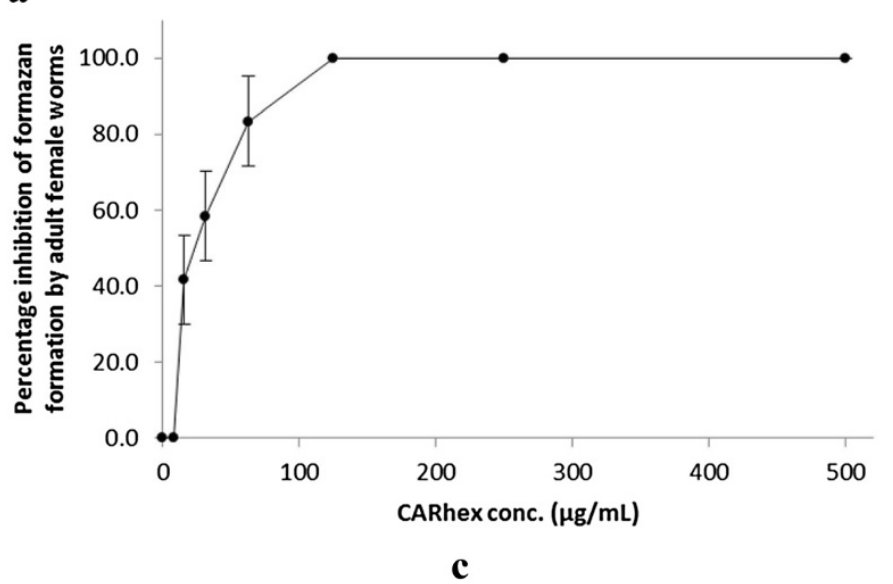

Figure 1 Effect of concentration of the essential oil of $C$. articulatus $\left(\mathrm{CAR}_{\mathrm{hex}}\right)$ on $\mathbf{O}$. ochengi viability. The viabilities of parasites in cultures were determined in the presence of different concentrations of the essential oil. Microfilarial motility (a), adult male worm motility (b) and inhibition of formazan formation (corresponding to worm death) in adult female worms (c) after 120 hours incubation were determined. 
Table 3 IC $_{50}, I_{100}$ and Selectivity Indices (SI) of the essential oil on 0 . ochengi

\begin{tabular}{lcccc}
\hline Parameter & Microfilariae & $\begin{array}{c}\text { Adult male } \\
\text { worm }\end{array}$ & $\begin{array}{c}\text { Adult } \\
\text { female } \\
\text { worm }\end{array}$ & $\begin{array}{c}\text { Monkey } \\
\text { kidney cells } \\
\text { (LLC-MK2) }\end{array}$ \\
\hline $\mathrm{IC}_{50}(\mu \mathrm{g} / \mathrm{ml})$ & 23.4 & 23.4 & 31.25 & 93.7 \\
$\mathrm{IC} \mathrm{C}_{100}(\mu \mathrm{g} / \mathrm{ml})$ & 62.5 & 62.5 & 125 & 250 \\
$\mathrm{SI}=\mathrm{I} \mathrm{C}_{50} \mathrm{MKC} / \mathrm{IC}_{50}$ & 4.0 & 4.0 & 2.99 & - \\
worm & & & & \\
\hline
\end{tabular}

SI (Selectivity Index $)=I C_{50}$ on mammalian cells/ $I C_{50}$ on parasite.

Table 3 summaries the inhibitory effect of the oil on $O$. ochengi microfilariae and adult worms, and the monkey kidney cells, indicating the inhibitory concentration (IC) and selectivity index (SI) values. The oil was moderately cytotoxic on the monkey kidney cells.

Acute oral toxicity test of the essential oil in mice

Figure 2 shows the effect of the essential oil on the mean weight of six Balb/c mice after limit dosing by gavage (2000 mg/kg body weight). Only one out of the six mice dosed with the oil had rough fur, lost weight slightly and initially and then started gaining weight 4 days after the extract administration. All other mice dosed with the essential oil were active and healthy and gained weight continuously. Individual cage-side observations showed no other abnormalities. No mouse died during follow-up for14 days. All the mice given 2\% DMSO in distilled water (control group) gained weight continuously.

\section{GC/MS analysis of the essential oil}

Table 4 gives the chemical composition of the essential oil of the roots/rhizomes of $C$. articulatus. GC/MS analysis revealed more than 80 compounds with monoterpenes, sesquiterpenes, hydrocarbons, fatty acids and fatty acid derivatives being the most abundant.

\section{Discussion}

The present study was carried out to investigate the acclaimed antifilarial activity of roots and rhizomes of Cyperus articulatus in the traditional treatment of onchocerciasis in North Western Cameroon and to assess the potential of the plant as a new source of novel O. volvulus filaricidal lead compounds. Solvents of increasing polarity (hexane, methylene chloride and methanol) were sequentially used to produce three crude extracts from the roots/rhizomes of $C$. articulatus. The hexane extract (an essential oil) was the most active, showing activity against microfilariae and adult worms in a dose dependent manner. The oil was apparently more active against adult males $\left(\mathrm{IC}_{50}=23.4 \mu \mathrm{g} / \mathrm{ml}\right)$ than adult females $\left(\mathrm{IC}_{50}=31.25 \mu \mathrm{g} / \mathrm{ml}\right.$ ) (Table 3 ), probably because motility reduction (used in assessing the males) is different from biochemical death (used in assessing the females).

This activity shows that the roots/rhizomes contain anti-Onchocerca principles and justifies their use in the traditional treatment of human onchocerciasis in the area. Thus, a search for novel filaricides from the plant materials should be focused on the non-polar extract. This is in contrast to the practice by herbalists who use the polar solvent, water in preparing the decoctions, indicating that their extraction procedure may be grossly inefficient [20]. The use of oils in extraction (assuming compounds remain stable) or addition of edible oils in preparation of the decoction may improve on yield and overall efficacy in the traditional medicine practice. Most herbalists around the world rely heavily on use of the universally available and safe solvent, water in the preparation

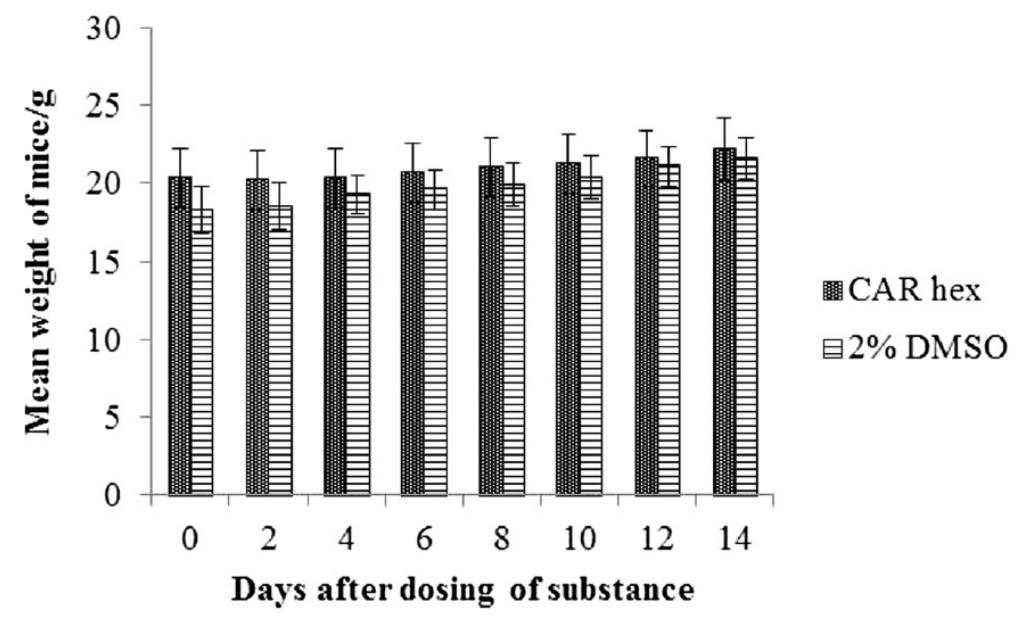

Figure 2 Effect of essential oil of $C$. articulatus $\left(C_{A R} R_{\text {hex }}\right)$ on Balb/c mice. The mean weights of six mice after administration of a single limit dose of $2000 \mathrm{mg} / \mathrm{kg}$ body weight of mouse were determined over a 14 day period. The negative control mice ( 6 animals) were dosed with diluent (2\% DMSO) only. 
Table 4 Chemical composition of essential oil (hexane extract) from roots/rhizomes of C. Articulatus

\begin{tabular}{|c|c|c|}
\hline \multicolumn{3}{|l|}{ Monoterpenes } \\
\hline Compound (Chemical name) & Retention time (RT) min & Nature of compound \\
\hline Camphenol, 6- & 4.4913 & Monoterpene alcohol \\
\hline Bicyclo[3.1.1 ]heptan-3-ol, 6,6-dimethyl-2-methylene-, [1S-(1 à,3à,5à)]- & 4.7638 & -do- \\
\hline Bicyclo[3.1.1 ]hept-3-en-2-ol, 4,6,6-trimethyl-, [1S-(1 à,2a,5à)]- & 4.8523 & - do- \\
\hline Bicyclo[3.1.0]hexan-3-ol, 4-methylene-1-(1-methylethyl)-, [1.S-(1 à,3a,5à)]- & 4.9535 & - do- \\
\hline$(-)-$ Myrtenol & 5.8193 & - do- \\
\hline Bicyclo[3.1.0]hex-3-en-2-one, 4-methyl-1-(1-methylethyl)- & 6.0775 & Monoterpene ketone \\
\hline Bicyclo[3.1.1 ]hept-3-en-2-one, 4,6,6-trimethyl-,(1S)- & 6.0815 & - do- \\
\hline 3,5-Heptadienal, 2-ethylidene-6-methyl- & 6.2340 & Monoterpene aldehyde \\
\hline Bicyclo[4.4.0]dec-2-ene-4-01, 2-methyl-9-(prop-1-en-3-01-2-yl)- & 15.8243 & \\
\hline \multicolumn{3}{|l|}{ Sesquiterpenes } \\
\hline Isolongifolene, 9,10-dehydro- & 9.0658 & Hydroxy compound \\
\hline Copaene & 9.2450 & \\
\hline a-Cubebene & 9.3067 & \\
\hline Cadina-1 (10),6,8-triene & 9.3247 & \\
\hline 7-Tetracyclo[6.2.1.0(3.8)O(3.9)] undecanol, 4,4,11,11-tetramethyl- & 11.0275 & Sesquiterpene alcohol \\
\hline Naphthalene, 1,2,3,4,4a,5,6,8a-octahydro-7 -methyl-4-methylene-1-(1-methylethyl)-, (1à,4aà,8aà)- & 11.1640 & \\
\hline Naphthalene, 1,2,3,4-tetrahydro-1 ,6-dimethyl-4-(1-methylethyl)-, (1S-cis)- & 11.2919 & \\
\hline (+)-Epi-bicyclosesquipheliandrene & 11.5152 & \\
\hline 2,3,4-Trifluorobenzoic acid, 4-nitrophenyl ester & 11.6408 & \\
\hline 7-Tetracyclo[6.2.1.0(3.8)0(3.9)]undecanol, 4,4,11,11-tetramethyl- & 11.7243 & Sesquiterpene alcohol \\
\hline 2-Naphthalenemethanol, 1,2,3,4,4a ,8a-hexahydro-à, à,4a, 8-tetramethyl-, [2R-(2à,4aà,8aà)]- & 11.7325 & - do- \\
\hline Cycloisolongifolene, 8,9-dehydro- & 12.2912 & \\
\hline Caryophyllene oxide & 13.2509 & Sesquiterpene oxide \\
\hline Longipinocarvone & 13.7303 & \\
\hline 3-Isopropyl-6, 7-dimethyltricycio[4.4.0.0(2,8)]decane-9, 10-diol & 13.7752 & Sesquiterpene alcohol \\
\hline
\end{tabular}

Compound (Chemical name)

Retention time (RT) min Nature of compound Sesquiterpenes (cont'd)

cis-Z-a-Bisabolene epoxide

Longiverbenone

2,2,7,7 -Tetramethyltricyclo[6.2.1.0(1,6)]undec-4-en-3-one

Acetic acid, 3-hyd roxy-6-isopropenyl-4, 8a-dimethyl-1,2,3,5,6,7,8,

8aoctahydronaphthalen-2-yl ester

5( 1H)-Azulenone, 2,4,6,7,8, 8a-hexahydro-3, 8-dimethyl-4-( 1-methylethylidene)-, (8S-cis)-

Perhydrocyclopropa[e]azulene-4,5,6-triol, 1,1,4,6-tetramethyl

1 H-Cycloprop[e]azulen-7 -01, decahydro-1 1,7 -trimethyl-4-methylene-,

[1ar-(1 aà,4aà,7a,7aa,7bà)]-

(-)-Spathulenol

Corymbolone

Spiro[4.5]decan-7 -one, 1,8-dimethyl-8,9-epoxy-4-isopropyl-

$9 \mathrm{H}$-Cycioisolongifolene, 8-oxo-

2( 1H) Naphthalenone, 3,5,6,7,8, 8a-hexahyd ro-4, 8adimethyl-6-( 1-methylethenyl)-

E-15-Heptadecenal

$\begin{array}{ll}14.0907 & \text { Sesquiterpene epoxide } \\ 14.9277 & \\ 15.6833 & \text { Sesquiterpene ketone } \\ 15.7474 & \text { Sesquiterpene ester } \\ 15.7488 & \\ 15.8186 & \\ 15.8686 & \\ 15.8706 & \text { Sesquiterpene alcohol } \\ 15.9639 & \text { Sesquiterpene } \\ 16.1027 & \text { ketoalcohol } \\ 16.2514 & \text { Sesquiterpene ketone } \\ 16.2630 & \text { Sesquiterpene ketone } \\ 16.4377 & \text { Sesquiterpene aldehyde }\end{array}$




\section{Table 4 Chemical composition of essential oil (hexane extract) from roots/rhizomes of C. Articulatus (Continued)}

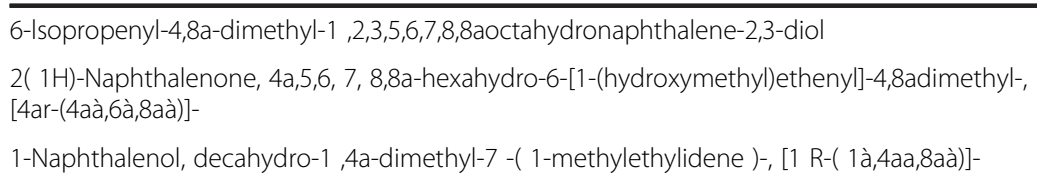

Polyterpenes

\begin{tabular}{|c|c|c|}
\hline Compound (Chemical name) & Retention time (RT) min & Nature of compound \\
\hline \multicolumn{3}{|l|}{ Hydrocarbons } \\
\hline 2,6-Dimethyl-1 ,3,5,7-octatetraene, E, E- & 3.0988 & Unsaturated hydrocarbon \\
\hline Benzene, 1-methyl-3-(1-methylethyl)- & 3.1698 & Aromatic hydrocarbon \\
\hline $\begin{array}{l}1 \text { H-Cycloprop[e]azulene, 1a,2,3,4,4a,5,6, 7boctahydro-1 ,1,4,7 -tetramethyl-, [1aR-(1aà,4à,4aa, } \\
\text { 7bà)]- }\end{array}$ & 9.7772 & - do- \\
\hline 3H-3a, 7-Methanoazulene, 2,4,5,6,7 ,8-hexahydro-1,4,9,9-tetramethyl-, [3aR-(3aà,4a,7à)]- & 9.8550 & - do- \\
\hline Benzene, 1-(1,5-dimethyl-4-hexenyl)-4-methyl- & 10.1253 & -do- \\
\hline Benzene, 1-methyl-4-(1 ,2,2-trimethylcyclopentyl)-,(R)- & 10.3648 & - do- \\
\hline Azulene, 1,2,3,5,6,7 ,8,8a-octahydro-1 ,4-dimethyl-7-(1-methylethenyl)-, [1 S-(1 à,7à,8aa)]- & 10.8948 & - do- \\
\hline a-Calacorene & 12.4888 & \\
\hline Octacosane & 29.3625 & \\
\hline \multicolumn{3}{|l|}{ Fatty acids } \\
\hline Oodecanoic acid & 14.0232 & \\
\hline n-Hexadecanoic acid & 19.4351 & Palmitic acid \\
\hline 9, 12-0ctadecadienoic acid (Z, Z)- & 21.5769 & Linoleic acid \\
\hline cis-13-0ctadecenoic acid & 21.6267 & \\
\hline $9,12,15$-0ctadecatrienoic acid, (Z, Z, Z)- & 21.6321 & \\
\hline cis-13-0ctadecenoic acid & 21.6355 & \\
\hline Octadecanoic acid & 21.7428 & \\
\hline Eicosanoic acid & 23.8517 & \\
\hline \multicolumn{3}{|l|}{ Esters } \\
\hline Isophthalic acid, di(2-methylprop-2-en-1-yl) ester & 11.5878 & \\
\hline Myrtenyl acetate & 23.3973 & \\
\hline Trichloroacetic acid, hexadecyl ester & 24.0485 & \\
\hline Bis(2-ethylhexyl)phthalate & 25.8520 & \\
\hline Oodecanoic acid, dodecyl ester & 26.0201 & \\
\hline (-)-trans-Pinocarvyl acetate & 27.9163 & \\
\hline Oodecanoic acid, tetradecyl ester & 28.0778 & \\
\hline Oodecanoic acid, hexadecyl ester & 30.1824 & \\
\hline
\end{tabular}

$\begin{array}{ll}16.4982 & \text { Sesquiterpene alcohol } \\ 18.5973 & \text { Sesquiterpene ketone } \\ 27.1088 & \text { Sesquiterpene alcohol }\end{array}$

22.6754

28.8145

Retention time (RT) min Nature of compound 
by Kuete and Efferth [21] indicated that terpenoids from Cameroonian plants showed best activities as antiparasitic agents. Nyasse and his group [22] also identified sesquiterpenes from $C$. articulatus collected from Cameroon. Extracts from plants may provide a natural combination of biologically active compounds responsible for the death of the parasite. The different compounds in the extract may be working in synergy to kill the parasite by providing an arsenal to multiple drug targets. For example, the present essential oil contains corymbolone (a sesquiterpene) and spathulenol which have been shown to exhibit anti-plasmodial [12] and antifungal [23,24], activities, respectively. Further studies are required to narrow down to the antifilarial principles in the essential oil. Although single pure compounds may inhibit particular molecular targets and even kill the parasite, they may be more susceptible to parasite resistance than an extract with possibly many active compounds. A number of other extracts from medicinal plants used in Cameroon have also been shown to exhibit antiOnchocerca activity $[25,26]$.

Although the essential oil from C. articulatus was moderately cytotoxic on monkey kidney cells, in the acute toxicity studies none of six mice died at the limit dose of $2000 \mathrm{mg} / \mathrm{kg}$ body weight, and only one was traumatized, probably by the drug administration procedure. This safety profile may imply a detoxification mechanism in the liver or kidneys in vivo. The finding in mice also lends credence to the ethnopharmacologically observed lack of toxicity or adverse effects in humans, at least in the short term.

\section{Conclusions}

The essential oil from the roots/rhizomes of $C$. articulatus is active against $O$. ochengi microfilariae and adult worms, hence may provide a source of new anti-filarial lead compounds. The results obtained also support the use of $C$. articulatus in traditional medicine for the treatment of human onchocerciasis.

\begin{abstract}
Abbreviations
Mfs: Microfilaraie; CCM: Complete culture medium; OECD: Organization for economic co-operation and development; CARhex: Hexane extract of the root/rhizomes of Cyperus articulatus.
\end{abstract}

\section{Competing interests}

The authors declare that they have no competing interests.

\section{Authors' contributions}

JAM collected the plants, took part in the preparation of the extracts and carried out the culture experiments, as well as analysed and interpreted the data. MS took part in the design of the culture experiments while JDN, SBB, GF and JM contributed in the preparation of the extracts and analysis of GC/ MS data. FCN did the conception, sought for funding, supervised the work and corrected the final manuscript. All authors read the manuscript, contributed in correcting it, and approved its final version.

\section{Acknowledgements}

This investigation received financial assistance from the UNICEF/UNDP/World Bank/WHO Special Programme for Research and Training in Tropical Diseases (TDR) (Project A70107). The authors are grateful to Evans Mainsah (University of Buea) and Pastor Denis Bughe of Sehn village, North West Cameroon, for the provision of ethnopharmacological information and collection of the plant investigated.

\section{Author details}

${ }^{1}$ ANDI Centre of Excellence, Biotechnology Unit, Faculty of Science, University of Buea, P.O. Box 63, Buea, Cameroon. ${ }^{2}$ Department of Chemistry, Faculty of Science, University of Buea, Buea, Cameroon. ${ }^{3}$ Department of Organic chemistry, Faculty of Science, University of Yaoundé I, Cameroon.

Received: 26 December 2013 Accepted: 30 June 2014 Published: 7 July 2014

\section{References}

1. World Health Organization: Global Initiative for the Elimination of Avoidable Blindness, Action Plan 2006 - 2011. WHO; 2007:29 [http://www.who.int/ blindness/Vision2020_report.pdf]

2. World Health Organization: Strategies for Ivermectin Distribution through Primary Health Care Systems, Document WHO/PBL/91.24. Geneva: WHO; 1991.

3. Richards FO, Miri E, Meredith S, Guderian R, Sauerbrey M, Remme H, Packard R, Ndiaye JM: Onchocerciasis. Bull World Health Organ 1998, 76(Suppl. 2):147-149.

4. Gardon J, Gardon-Wendel M, Demanga N, Kamgno J, Chippaux J, Boussinesq M: Serious reactions after mass treatment of onchocerciasis with ivermectin in an area endemic for Loa loa infection. Lancet 1997, 350:18-22.

5. Lizotte-Waniewski M, Tawe W, Guiliano D, Lu W, Williams SA, Lustigman S: Identification of potential vaccine and drug target candidates by expressed sequence tag analysis and immunoscreening of $O$. volvulus larval cDNA libraries. Infect Immun 2000, 68(6):3491-3501.

6. Hoerauf A: Filariasis: new drugs and new opportunities for lymphatic filariasis and onchocerciasis. Curr Opin Infect Dis 2008, 21:673-681.

7. Wanji S, Tendongfor N, Theolbal N, Esum M, Che J, Nkaescheu A, Alassa F, Kamnang G, Enyong P, Taylor M, Hoerauf A, Taylor D: Community-directed delivery of doxycycline for the treatment of onchocerciasis in Cameroon in areas of co-endemicity with loiasis in Cameroon. Parasit Vectors 2009, 2:39.

8. Stingl P: Onchocerciasis: developments in diagnosis, treatment and control. Int J Dermatol 2009, 48:393-396.

9. Ebigwai JK, llondu EM, Markson AA, Ekeleme E: In vitro evaluation of the essential oil extract of six plant species and ivermectin on the microfilaria larva of Simulium yahense. Res J Med Plant 2012, 6:461-465.

10. Comley JCW: New macrofilaricidal leads from plants. Trop J Parasitol 1990, 59(1):77-83.

11. Oliver-Bever B: Medicinal Plants in Tropical West Africa. London: Cambridge University Press; 1986:123-169.

12. Rukunga GM, Muregi FW, Omar SA, Gathirwa JW, Muthaura CN, Peter MG, Heydenreich M, Mungai GM: Anti-plasmodial activity of the extracts and two sesquiterpenes from Cyperus articulatus. Fitoterapia 2008, 79(3):188-190

13. Oladusu LA, Usman LA, Olawore NO, Atata RF: Antibacterial activity of rhizomes essential oils from two types of Cyperus articulatus growing in Nigeria. Adv Biol Res 2011, 5(3):179-183.

14. Mongelli E, Desmarchelier C, Coussio J, Ciccia G: Antimicrobial activity and interaction with DNA of medicinal plants from the Peruvian Amazon region. Rev Argent Microbiol 1995, 27(4):199-203.

15. Bum NE, Schmutz M, Meyer C, Rakotonirina A, Bopelet M, Portet C, Jeker A, Rakotonirina SV, Olpe HR, Herrling P: Anticonvulsant properties of the methanolic extract of Cyperus articulatus (Cyperaceae). J Ethnopharmacol 2001, 76(2):145-150.

16. Trees AJ, Graham SP, Renz A, Bianco AE, Tanya V: Onchocerca ochengi infections in cattle as a model for human onchocerciasis: Recent developments. Parasitolology 2000, 120:5133-5142.

17. Cho-Ngwa F, Daggfeldt A, Titanji VPK, Gronvik K: Preparation and characterization of specific monoclonal antibodies for the detection of adult worm infections in onchocerciasis. Hybridoma 2005, 24(6):283-290. 
18. Comley JCW, Townson S, Rees MJ, Dobinson A: The further application of MTT-formazan colorimetry to studies on filarial viability. Trop Med Parasitol 1989, 40:311-316.

19. Organization for Economic Co-operation and Development (OECD): Guidelines for the Testing of Chemicals. Paris: 2001. Monograph No 423.

20. Gupta A, Naraniwal M, Kothari V: Modern extraction methods for the preparation of plant extracts. Int J App/ Nat Sci 2012, 1(1):8-26.

21. Kuete V, Efferth T: Cameroonian medicinal plants: pharmacology and derived natural products. Front Pharmacol 2010, 1:123.

22. Nyasse $B$, Tih RG, Sodengam BL, Martins MT, Bodo R: Mandassindione and other sesquiterpenic ketones from Cyperus articulatus. Phytochemistry 1988, 27:3319-3321.

23. Al-Ja'fari AH, Vila R, Freixa B, Tomi F, Casanova J, Costa J, Caniqueral S: Composition and antifungal activity of the essential oil from the rhizome and roots of Ferula hermonis. Phytochemistry 2011, 74(11-12):1406-1413.

24. Waikedre J, Vitturo Cl, Molina A, Theodoro PN, Do Rosário Rodrigues Silva M, Espindola LS, Maciuk A, Fournet A: Antifungal activity of the essential oils of Callitris neocaledonica and C. sulcata heartwood (Cupressaceae). Chem Biodivers 2012, 9(3):644-653.

25. Titanji VPK, Evehe MS, Ayafor JF, Kimbu SF: Novel Onchocerca volvulus filaricides from Carapa procera, Ployalthia suaveolens and Pachypodanthium staudtii. Acta Leiden 1990, 59:377-382.

26. Cho-Ngwa F, Abongwa M, Ngemenya NM, Nyongbela KD: Selective activity of extracts of Margaritaria discoidea and Homalium africanum on Onchocerca ochengi. BMC Complement Altern Med 2010, 10:62.

doi:10.1186/1472-6882-14-223

Cite this article as: Metuge et al:: Anti-Onchocerca activity and phytochemical analysis of an essential oil from Cyperus articulatus L. BMC Complementary and Alternative Medicine 2014 14:223.

\section{Submit your next manuscript to BioMed Central and take full advantage of:}

- Convenient online submission

- Thorough peer review

- No space constraints or color figure charges

- Immediate publication on acceptance

- Inclusion in PubMed, CAS, Scopus and Google Scholar

- Research which is freely available for redistribution 